\title{
Retrieval of Marine Stratus Cloud Droplet Size from NOAA-AVHRR Nighttime Imagery
}

\author{
Juan C. Pérez," Félix Herrera, "Fernando Rosa, Albano González," \\ Melanie A. Wetzel, ${ }^{\dagger}$ Randolph D. Borys,${ }^{\dagger}$ and \\ Douglas H. Lowenthal ${ }^{\dagger}$
}

\begin{abstract}
A method for retrieval of the droplet radius and temperature of oceanic stratocumulus is presented. It is based on night imagery obtained from the infrared channels of NOAA-AVHRR and an atmospheric radiative transfer model that makes use of the discrete ordinate method DISORT. It uses the observed satellite brightness temperature differences (BTD) between channels 4 and 5 to obtain the cloud temperature and between channels 3 and 4 to extract the effective radius of the cloud droplets. We also studied the peculiarities of the method, taking into account the behavior of the single scattering parameters, deduced from Mie theory, with droplet size. Results obtained are compared with in situ data collected at the Canary Islands (Spain) during summer 1996. CElsevier Science Inc., 2000
\end{abstract}

\section{INTRODUCTION}

Clouds play an important role in the radiation budget of the atmosphere and surface. Radiative transfer calculations have been used to develop models to extract the optical parameters of clouds, since the radiative transfer process through the atmosphere relies on the geometric and optical properties of clouds. The most important parameters of clouds include the macroscopic (e.g., fractional coverage, height, and thickness) and the micro-

\footnotetext{
*Dpto. Física Fundamental y Experimental, Universidad de La Laguna, Tenerife, Islas Canarias, Spain

† Atmospheric Sciences Center, Desert Research Institute, Reno, NV

Address correspondence to Juan C. Pérez, Lab. de Comunicaciones y Teledetección, Dpto. Física Fundamental y Experimental, Univ. de La Laguna, 38203, Tenerife, Islas Canarias, Spain. E-mail: jcperez@ ull.es

Received 5 August 1999; revised 15 November 1999.
}

scopic, including water content, droplet size, and its phase. In turn, the sizes and number of droplets are related with the cloud condensation nuclei (CCN) concentration present during the cloud formation (Twomey, 1977; Twomey et al., 1984). In recent years, data from multispectral radiometers have been used to extract these parameters, especially data provided by the Advanced Very High Resolution Radiometer (AVHRR) on board National Oceanic and Atmospheric Administration (NOAA) operational satellites.

Numerous studies have addressed getting the parameters that characterize clouds of very different nature, from fog (Wetzel et al., 1996) to cirrus (Ou et al., 1993), including midlevel and low clouds, such as stratocumulus, and even overlapping clouds at different heights (Baum et al., 1994). Relationships between the different satellite channels are used in both the visible and the infrared regions, to obtain the microscopic and macroscopic parameters.

For the present work, we accomplished a detailed study of the retrieval of cloud parameters (effective radius and mean temperature) starting from AVHRR infrared channels and a radiative transfer model. This study has been developed for night imagery, due to the simpler interpretation of data provided by AVHRR channel 3 $(3.7 \mu \mathrm{m})$. Due to its spectral range, the radiance received by this sensor is the sum of two contributions, one from solar radiation reflected by the earth's surface and atmosphere and the other from the electromagnetic energy emitted by these targets (thermal emission). For daytime analysis the interpretation of the upwelling radiance corresponding to this band is complicated by the significant solar radiation scattered by particles of clouds, although recent studies have addressed methods to split out both of these contributions to the total radiance detected by the sensor (Rao et al., 1995, Herrera et al., 1999). 

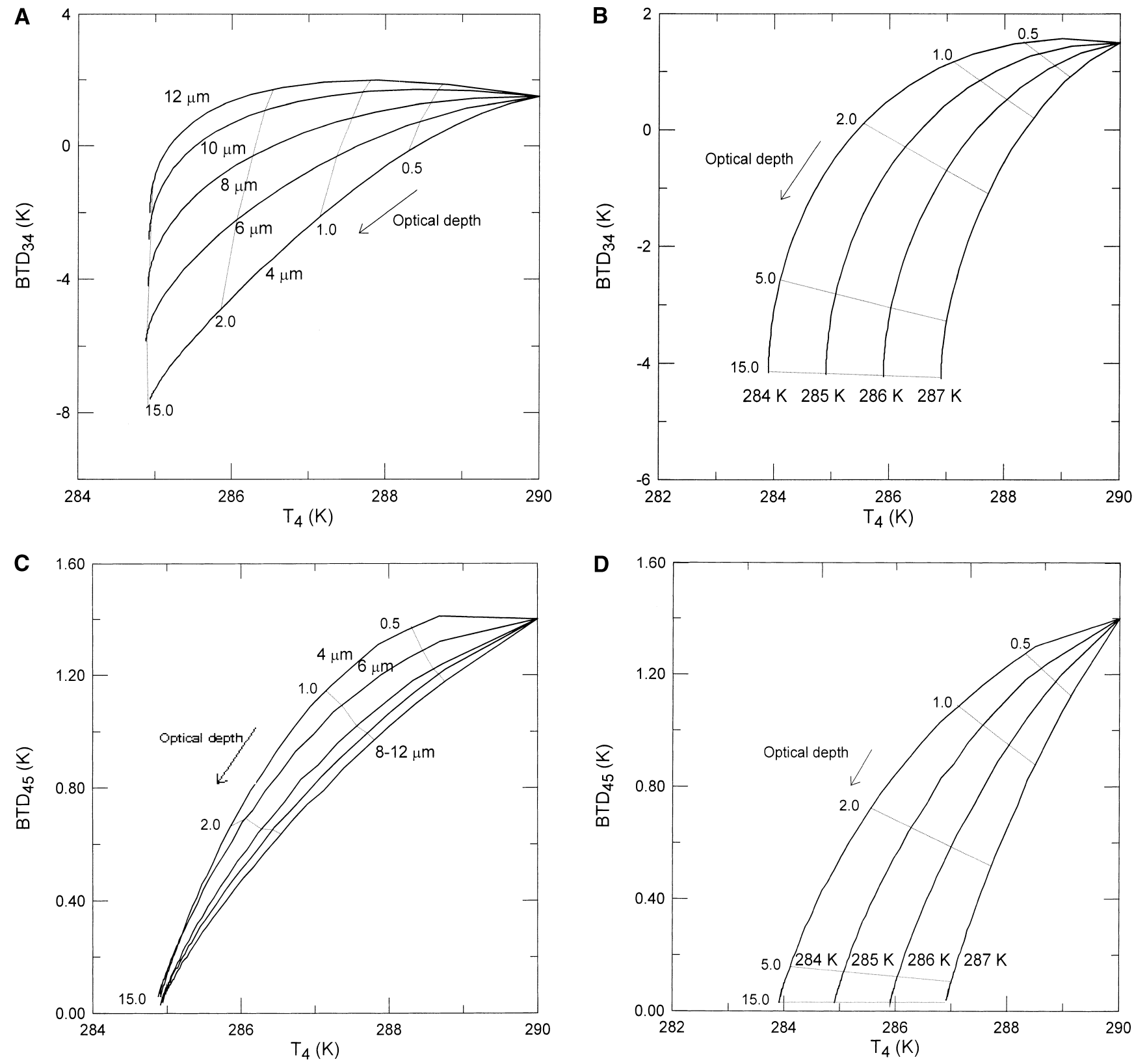

Figure 1. Theoretical brightness temperature differences (BTD). Dependence of BTD $_{34}$ on (a) effective radius of cloud drop-

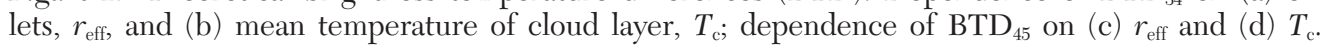

This study is applied to data corresponding to the Canary Islands region, at approximately $28^{\circ} \mathrm{N}, 16^{\circ} \mathrm{W}$, in the North Atlantic near the northwest coast of Africa. The specific clouds of the Canarian Archipelago, in particular those in the north side of the islands of higher orography, are due to a stratocumulus layer, denominated sea of clouds, that reaches a notable horizontal development but whose thickness is quite variable due to dynamic factors, such as the stability of the atmosphere, and geographic factors, such as altitude and orientation of the mountains (Marzol et al., 1994). Of the factors contributing to the formation of this cloud cover, the most important is the subsidence thermal inversion characteristic of the Alisios regime.

The sea of clouds does not maintain the same features all year long, being more frequent but shallower in summer. The thickness increases in spring, autumn, and winter due to the invasion of polar marine air, and diminishes in summer due to the frequent advections of warm air from Sahara. Cloud top altitude also varies, reaching as much as $2000 \mathrm{~m}$ in winter but seldom exceeding $1100 \mathrm{~m}$ in summer, because the moist inferior Alisios layer is compressed by the subsident air (Marzol et al., 1988) - the upper Alisios layer being warmer and dry. 


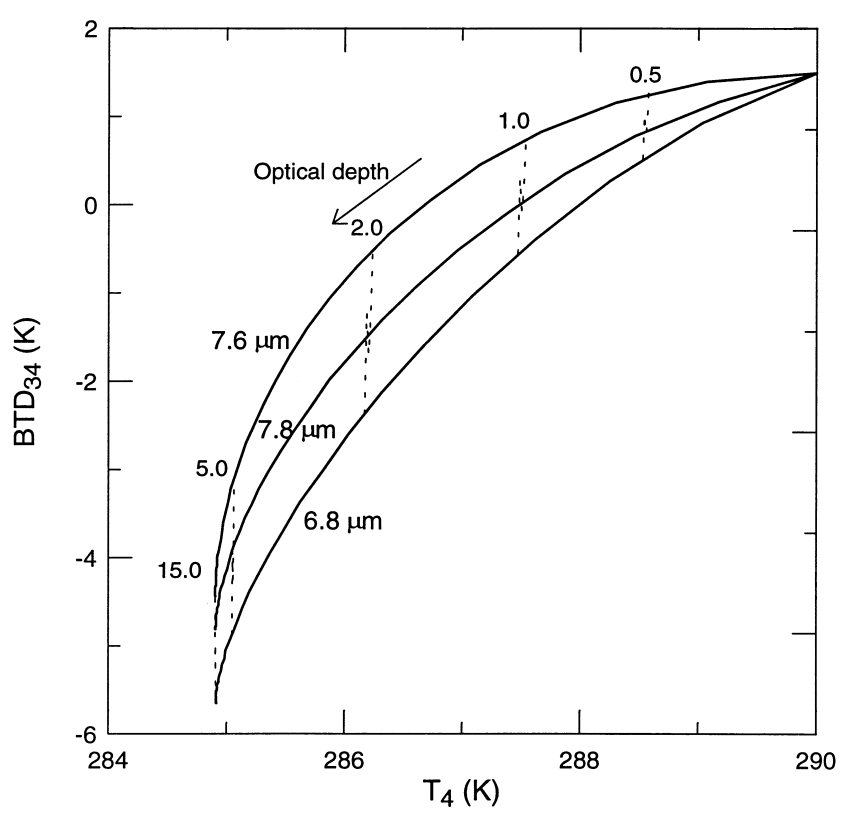

Figure 2. Dependence of $\mathrm{BTD}_{34}$ on effective radius of cloud droplets showing nonmonotonic behavior.

We present the basic radiative transfer theory and the results supplied by the numerical model. These results are expressed as brightness temperatures differences (BTD) deduced from the simulated radiances obtained for AVHRR channels $3(3.78 \mu \mathrm{m}), 4(10.8 \mu \mathrm{m})$, and $5(12.0 \mu \mathrm{m})$. Results are presented in terms of BTD between channels 3 and $4\left(\mathrm{BTD}_{34}\right)$ and between channels 4 and $5\left(\mathrm{BTD}_{45}\right)$ versus channel 4 temperature $\left(T_{4}\right)$. This model is used to retrieve the effective droplet ra- dius and mean temperature of the cloud layer. These results are compared with in situ measurements taken in the summer of 1996 by the Desert Research Institute of Nevada in the north of Tenerife Island (Canary Islands, Spain). Finally, we study the applicability of this procedure to satellite data through a sensitivity analysis.

\section{RADIATIVE TRANSFER MODEL}

The development of a method to extract the macroscopic and microscopic parameters of a cloudy cover requires a numerical model for the theoretical calculation of radiance that reaches the top of the atmosphere. However, the exact representation of the earth-atmosphere system is very complex due to the variety of components that must be taken into account. It is therefore necessary to make a set of assumptions that allows us to characterize the cloud cover, the surface under it, and the remainder of the atmosphere through which radiation propagates to reach the satellite.

Let us consider a planar homogeneous cloud layer, parallel to the surface, also considered homogeneous and with an emissivity of 1 . We also suppose that the atmosphere over the cloud is a clear window and the layer located between the surface and the cloud is composed only of water vapor. As noted above, the subsidence inversion in Canary region tends to limit the majority of water vapor to below the cloud top.

In general, clouds are a semitransparent medium, so that the radiance received by the sensor is the addition of two components, the cloud itself and the underlying surface. Under dry and cloudless atmospheric conditions,

Figure 3. Normalized area between the theoretical curves for several effective radii and horizontal axis in the diagram: (a) BTD ${ }_{34}$; (b) $\mathrm{BTD}_{45}$.
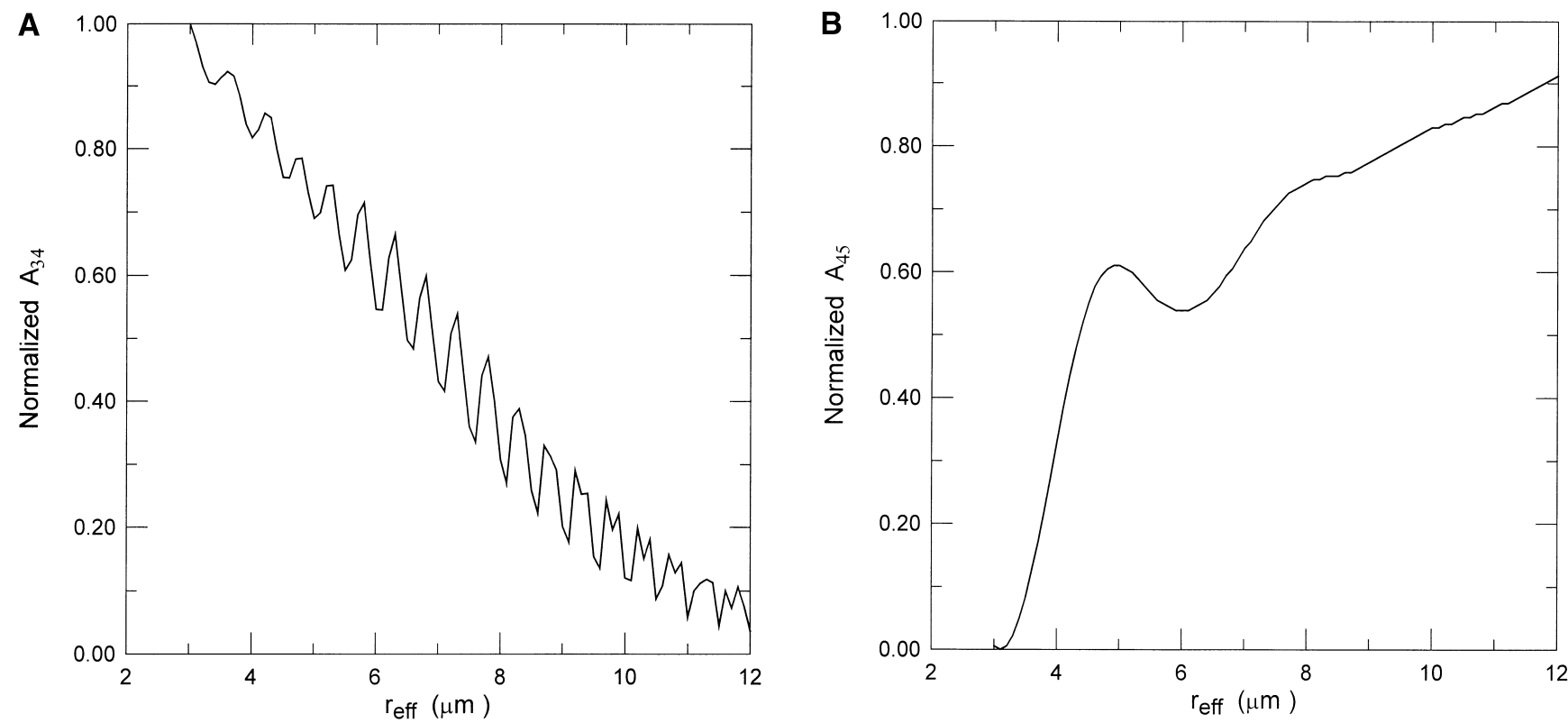


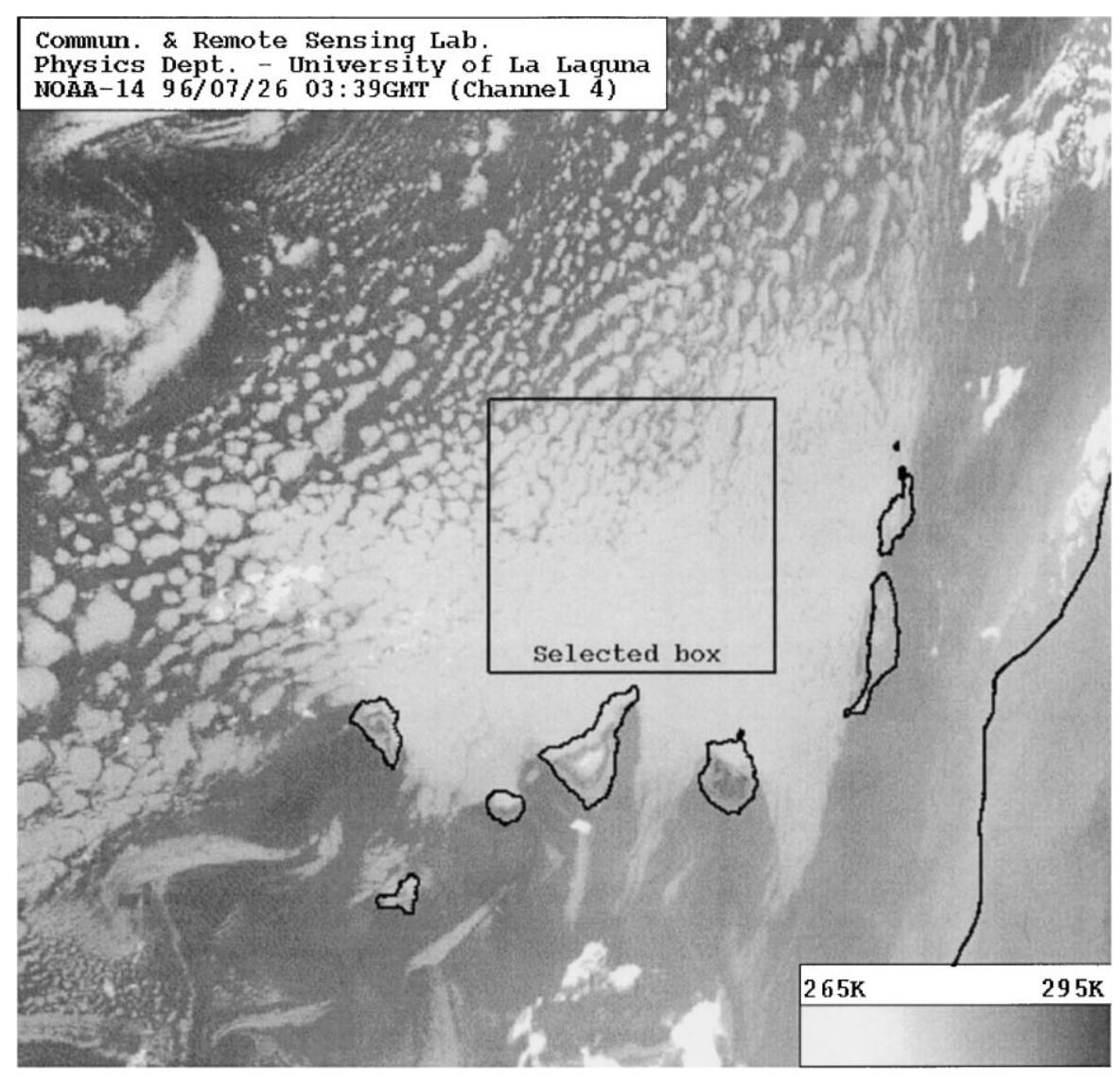

Figure 4. AVHRR channel 4 image of Canary Islands region on 26 July 1996. The box outlined is the image analysis area, with a large area covered by stratocumulus and located near the groundbased sampling site. the brightness temperature differences between the thermal channels of the AVHRR are typically small over most surfaces. As moisture increases, the differences between the temperatures obtained in the different channels become larger, as channel 5 appears colder than channel 4, which in turn has a temperature lower than channel 3 (Hutchison et al., 1991). The atmospheric attenuation is greater at $12 \mu \mathrm{m}$ than at $10.8 \mu \mathrm{m}$, and 3.7 $\mu \mathrm{m}$ experiences the lowest attenuation. Therefore, the radiance that reaches the bottom of a cloud layer is affected in different ways for each satellite band.

Stratocumulus are modeled as being composed of spherical water droplets with a gamma size distribution and an effective radius $r_{\text {eff }}$ defined as (Hansen and Travis, 1974)

$$
r_{\text {eff }}=\frac{\int_{0}^{\infty} r^{3} n(r) \mathrm{d} r}{\int_{0}^{\infty} r^{2} n(r) \mathrm{d} r}
$$

where $n(r)$ is the cloud droplet concentration with radius between $r$ and $r+\mathrm{d} r$. To account for the geometrical cloud thickness and the total concentration of particles, we will make use of the optical thickness, $\tau$, defined by

$$
\tau=\int Q_{\mathrm{e}}(r / \lambda) \pi r^{2} n(r) \mathrm{d} r \Delta h
$$

where $\Delta h$ is the geometrical thickness of the layer and $Q_{\mathrm{e}}$ is the extinction efficiency that, for spherical particles, could be calculated following the Mie scattering theory
(Wiscombe, 1980, Nussenzveig and Wiscombe, 1980, Bohren and Huffman, 1983). We used the complex refractive index for water reported by Seglestein (1981) for the wavelengths corresponding to each channel. This optical thickness will be specified for channel $4(10.8 \mu \mathrm{m})$, obtaining from it the corresponding values for channels 3 and 5 according to the relationship between the respective extinction efficiencies:

$$
\tau_{(3,5)}=\frac{Q_{\mathrm{e}(3,5)}}{Q_{\mathrm{e}(4)}} \tau_{4}
$$

We calculate from Mie's theory the single scattering albedo (percentage of the incident beam that will be scattered in each scattering event), as well as the angular distribution of the scattered energy, represented by the phase function. This is computed from the Legendre polynomial expansion (Dave, 1970).

In this way, given the characteristic parameters of cloud droplets, we applied a radiative transfer numerical method with the aim of simulating the theoretical radiances received by satellite. We used a multiple scattering radiative transfer model based on the discrete ordinates method (DISORT) (Stamnes et al., 1988, Tsay et al., 1990). This method includes the effects of multiple scattering, absorption, and emission within an atmospheric layer, assuming that the atmosphere consists of a certain number of homogeneous adjacent layers, where for each layer the single scattering properties are constant. 

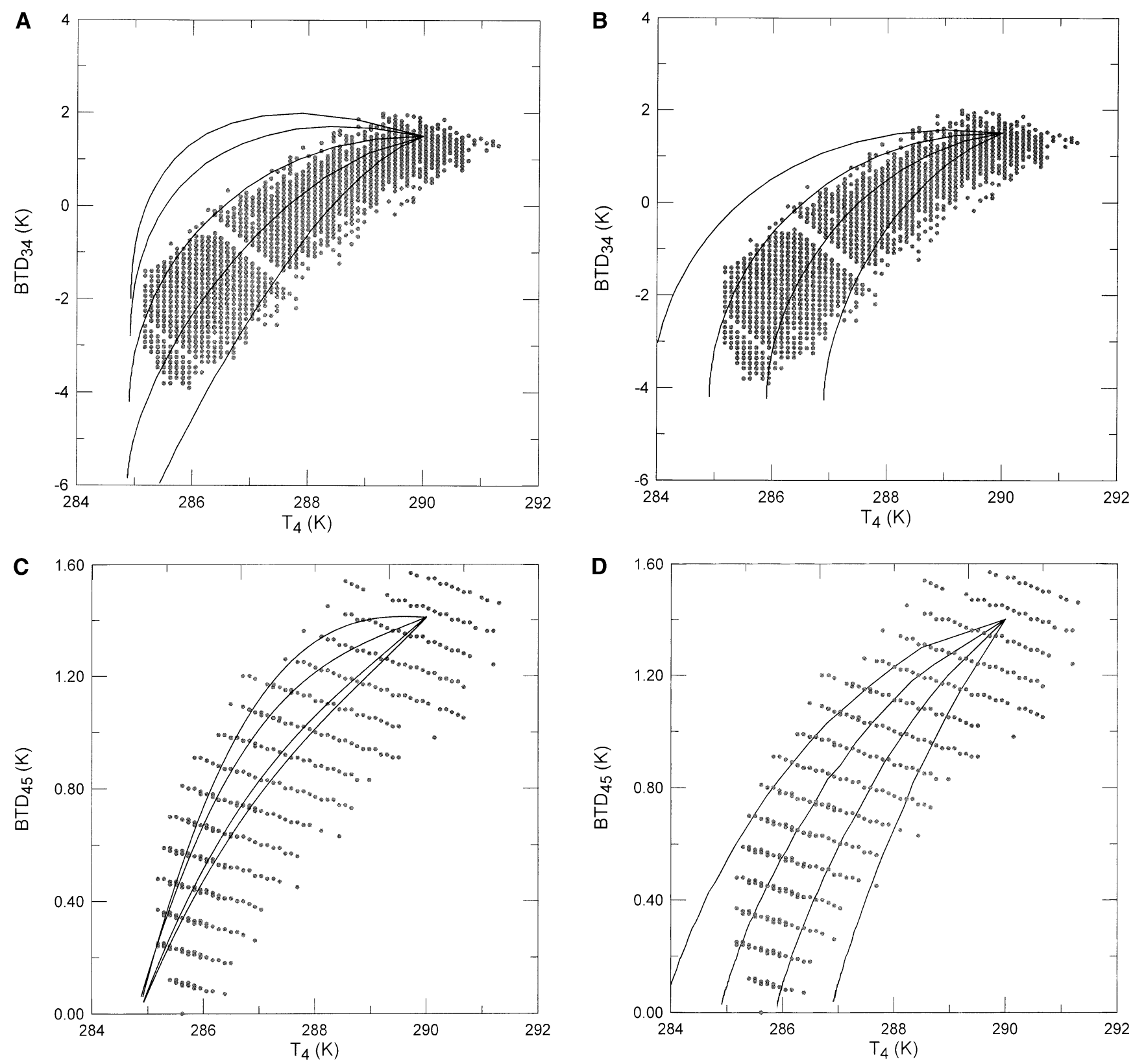

Figure 5. Same curves as in Fig. 1, superimposed on satellite data for case A image.

Once the simulated radiances are obtained, the corresponding brightness temperatures are calculated for the central wavelengths of three bands (channels 3, 4, and 5) of the AVHRR through the Planck function. To study more directly the radiative differences between these channels, we used diagrams of the brightness temperature differences, specifically between channels 3 and $4\left(\mathrm{BTD}_{34}\right)$ and between channels 4 and $5\left(\mathrm{BTD}_{45}\right)$. Both are represented as a function of channel 4 temperature $\left(T_{4}\right)$.

\section{Model Behavior}

Here we present the results obtained by running the model described above. With this aim we will study the behavior of the BTD diagrams upon varying the charac- teristic parameters of the cloud: the effective radius of the particles, the mean temperature of the cloud layer, and its optical thickness.

To study the dependence of upwelling channel radiances with the effective radius of the droplets that compose the cloud, we ran simulations starting from a fixed temperature for the system formed by surface plus the portion of atmosphere under the cloud $\left(T_{s}\right)$, which is determined from clear-sky pixels. This temperature is different for each of the channels, because, as we have noted, the absorption of the water vapor is not constant for the different bands in the infrared and the radiance that arrives to the cloud bottom is modulated by this effect. To account for cloud optical thickness, we varied 

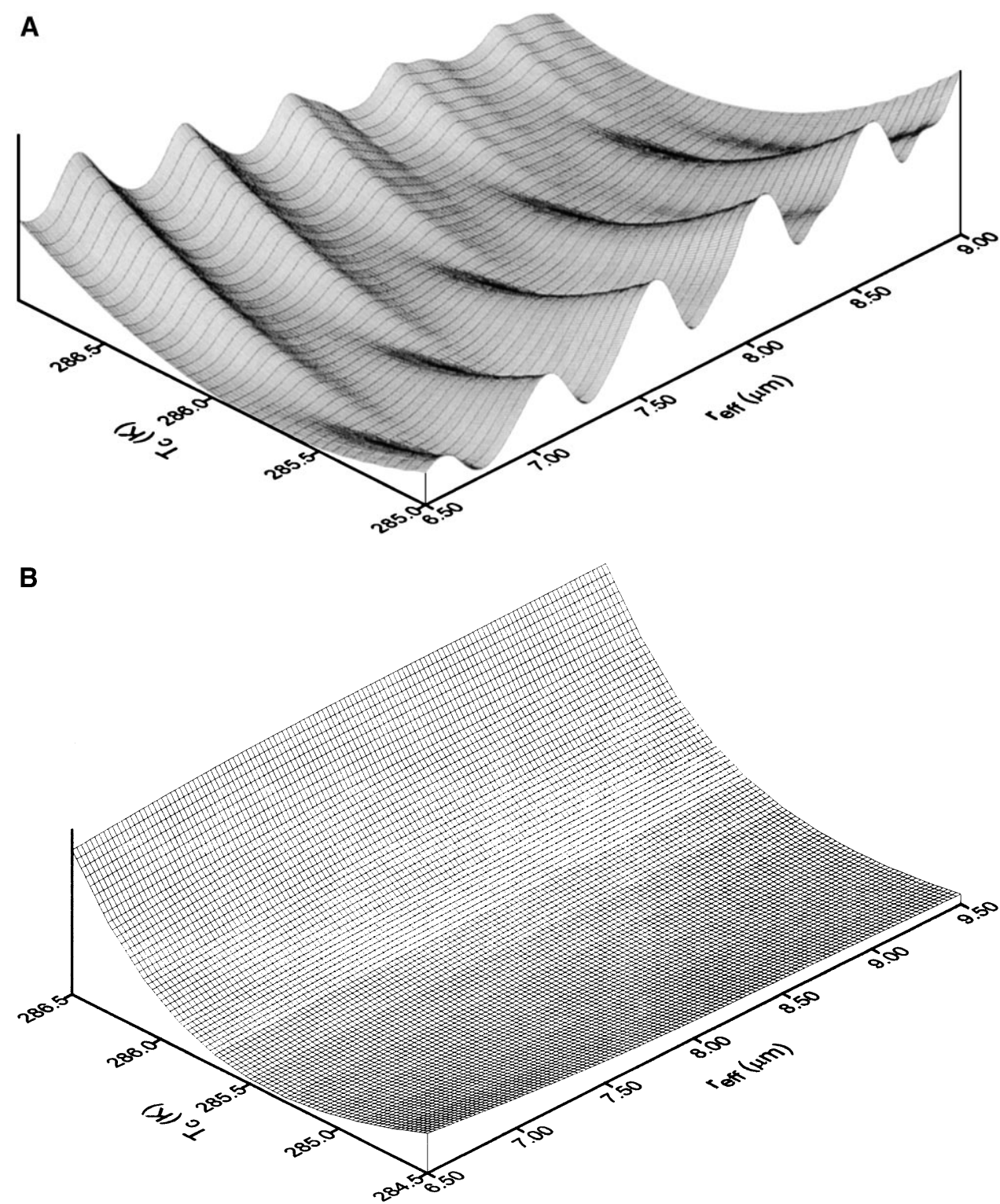

Figure 6. Sum of the distances of every point of the selected box for case A to theoretical curve for a range of effective radii and cloud temperatures (cost function): (a) $\mathrm{BTD}_{34}$ case; (b) $\mathrm{BTD}_{45}$ case.

the model optical thickness for channel 4 from 0 to 50 , to simulate all cases between cloudless pixels and those containing clouds so dense or deep that they are opaque to the radiation.

Figure 1a shows the effect on the $\mathrm{BTD}_{34}$ vs. $T_{4}$ diagram of varying the effective droplet radius. These curves were obtained for a cloud temperature of $285 \mathrm{~K}$ and an under-cloud temperature $T_{\mathrm{s}}=290 \mathrm{~K}$ for channel 4 and $291.5 \mathrm{~K}$ for channel 3. For each of these curves we specified the cloud droplet size, while optical thickness was varied taking the values given above. The set of curves corresponds to effective radii of $4,6,8,10$, and $12 \mu \mathrm{m}$. These values were selected to show a general tendency, but detailed study was left for later investigations. It can be seen that, for small optical thickness, the radius influence is not very appreciable. Thus, curves are rather close together and near to the starting point that represents cloudless pixels. When optical thickness increases, the differences become more appreciable, although all of the curves reach the same temperature in channel 4 for great values of optical thickness. These differences are caused by the intrinsic properties of the cloud layer, because transmissivity, emissivity, and reflectivity depend on the droplet radii. As optical depth increases, $\mathrm{BTD}_{34}$ diminishes, passing through zero and becoming negative. This effect is mainly due to light scattering by cloud droplets. For large radii the behavior is similar to that presented by high clouds (Hutchison et al., 1995).

In the same way, it is necessary to know the model behavior for different values of the mean temperature of the cloud layer. Figure $1 \mathrm{~b}$ presents $\mathrm{BTD}_{34}$ vs. $T_{4}$ for a constant radius of $8 \mu \mathrm{m}$ and the same conditions as the previous case for $T_{s}$. The curves correspond to cloud 


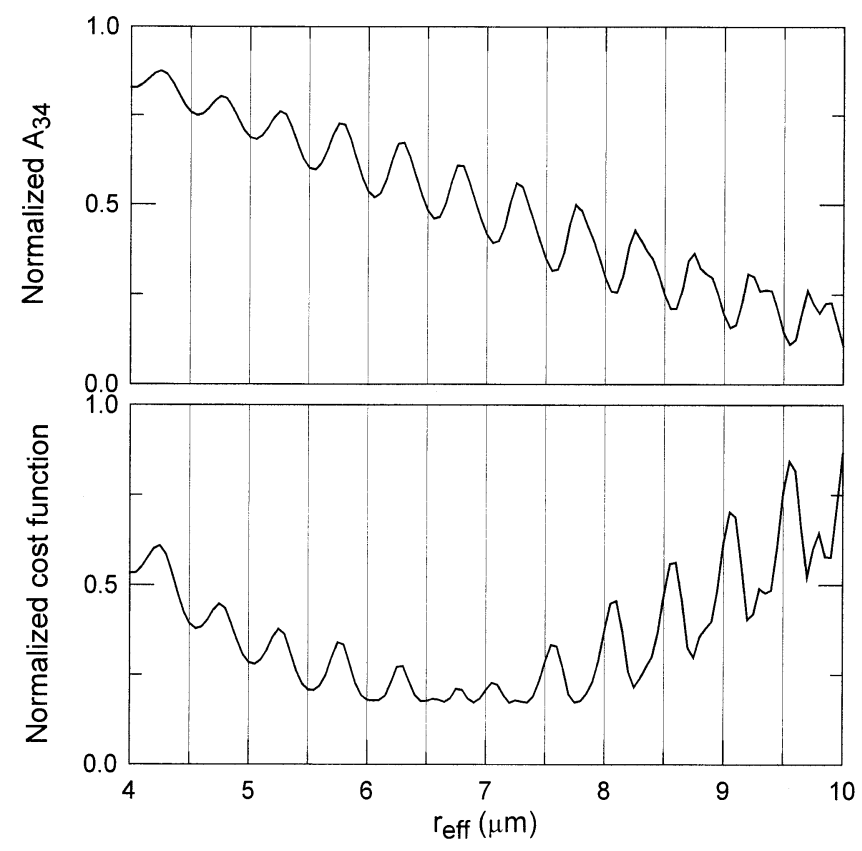

Figure 7. Phase changes of $\mathrm{BTD}_{34}$ cost function for case A, for $T_{\mathrm{c}}=285.2 \mathrm{~K}$, in relation to normalized area as explained under Model Behavior.

temperatures $T_{\mathrm{c}}=284,285,286$, and $287 \mathrm{~K}$. From this diagram it can be inferred that a small variation of $T_{\mathrm{c}}$ causes a significant displacement in the $\mathrm{BTD}_{34}$ characteristics.

A similar study has been conducted for the diagram BTD $_{45}$ vs. $T_{4}$. Figure 1c shows the behavior of the model for the same set of radii used in Fig. 1a. In this case, $T_{\mathrm{s}}$ for channel 5 is $288.6 \mathrm{~K}$. Note also that $\mathrm{BTD}_{45}$ reaches zero as optical thickness increases. This behavior differs from that seen for $\mathrm{BTD}_{34}$, as cloud layer scattering in the thermal infrared bands is practically negligible. Furthermore, the curves for different radii present less appreciable differences, since channels 4 and 5 of the AVHRR are near each other in the electromagnetic spectrum and so radiative parameters that characterize the droplets (single scattering albedo and phase function), extracted according to Mie theory, are similar. Regarding the influence of cloud temperature on the model, we can see in Fig. 1d that, as with $\mathrm{BTD}_{34}$, small variations in $T_{\mathrm{c}}$ imply large distances between curves. For this case, we used the same $T_{\mathrm{c}}$ values as in Fig. $1 \mathrm{~b}$.

At first glance, from Figs. 1a and 1c we can see a monotonic behavior upon varying the radius; that is, upon increasing $r_{\text {eff }}$ the curves are always displaced in the same direction. However, this appearance is due to the parameter discretization used to calculate the different curves, taking $r_{\text {eff }}$ in $2-\mu \mathrm{m}$ intervals. It might be assumed that, given a point between two of these curves, the corresponding radius would be obtained carrying out a simple interpolation. However, if we increase the number of curves, making the gap between radii smaller, we see that this is not so, because the displacement direction of the curves is no longer uniform with increasing radius. For example, in Fig. 2 we represent the curves corresponding to $r_{\text {eff }}=6.8,7.6$, and $7.8 \mu \mathrm{m}$ under the same conditions as in Fig. 1a. The curve corresponding to $r_{\text {eff }}=7.8 \mu \mathrm{m}$ does not follow the same tendency of BTD $_{34}$ with increasing $r_{\text {eff. }}$ A similar but smaller effect occurs for $\mathrm{BTD}_{45}$ (data not shown).

Figure 8. Case A scattergrams with the best fits obtained through the proposed method in both the (a) BTD 34 and $(\mathrm{b}) \mathrm{BTD}_{45}$ diagrams.
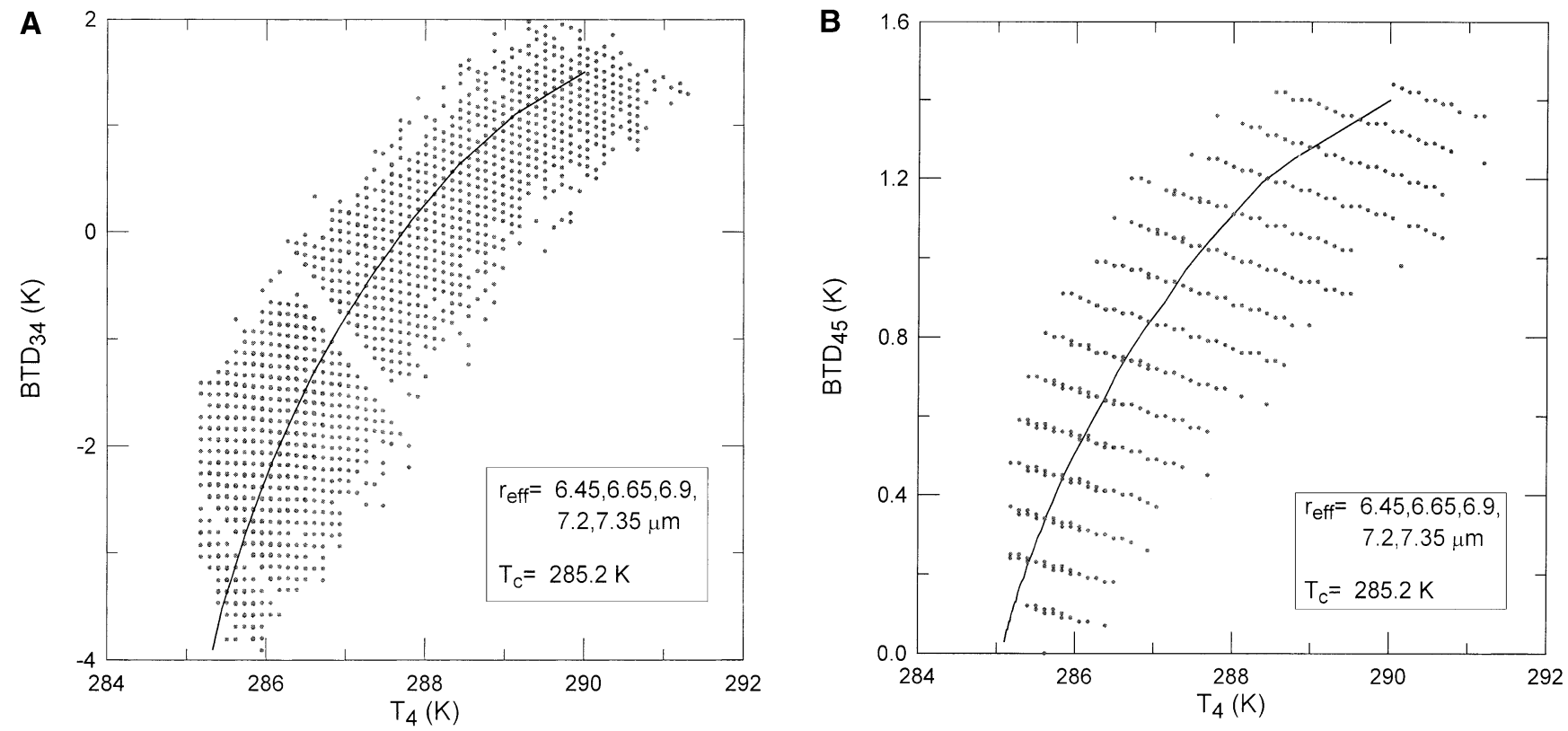


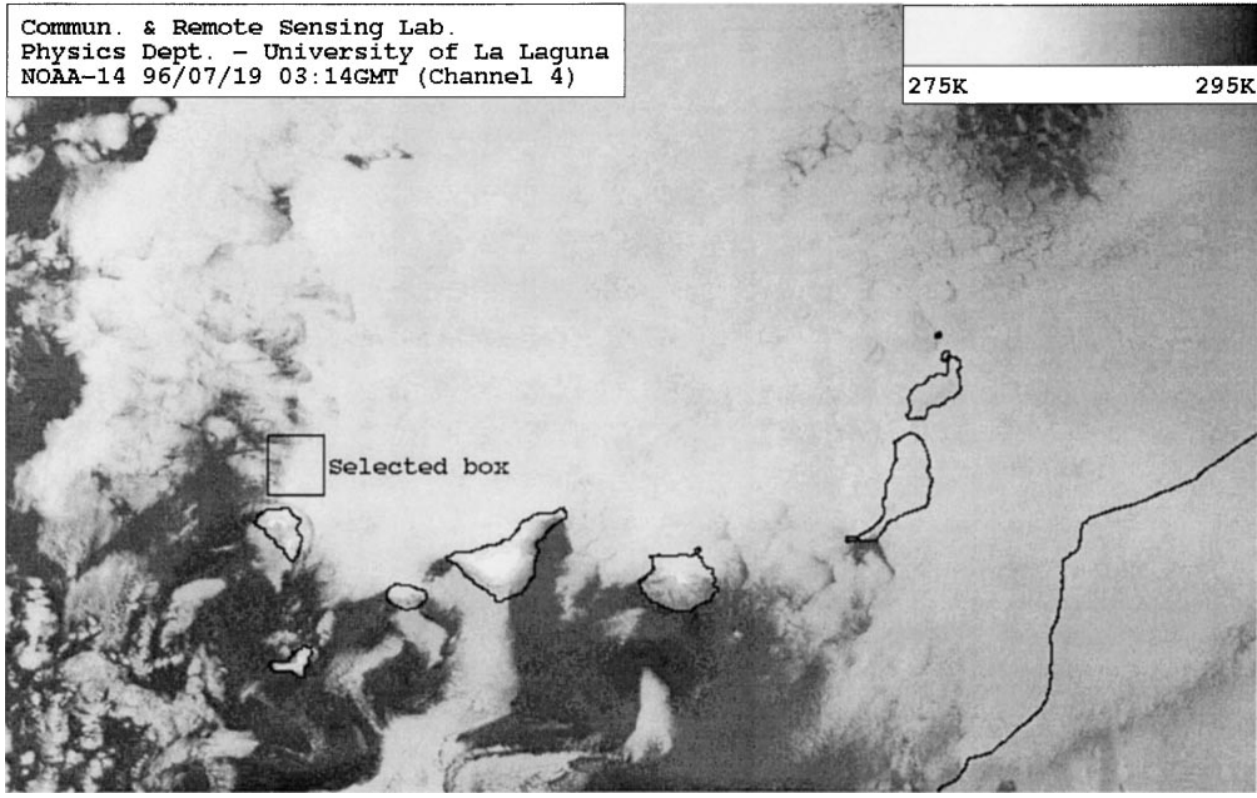

Figure 9. AVHRR channel 4 image of Canary Islands region on 19 July 1996. Note that the selected box is displaced from the ground-based sampling site on Tenerife due to the requirements of the proposed method (both cloudless pixels and dense clouds present in the box).
To make a more detailed analysis of the position of model curves upon varying the effective radius, we represent the area included between each curve and the straight line parallel to abscissa axis that includes the point that characterizes the cloudless pixel, in a similar way to Wen and Rose (1994). This is possible because all curves reach the same channel 4 temperature for a fixed $T_{\mathrm{c}}$. These calculations give us a function $A_{34}(r)$, dependent on the effective radius that is related with the position of each of the curves within the diagram. In Fig. 3a this normalized function is represented opposite the

Figure 10. BTD $_{34}$ cost function for case $\mathrm{B}$, for a mean temperature of cloud layer $T_{\mathrm{c}}=284.45 \mathrm{~K}$.

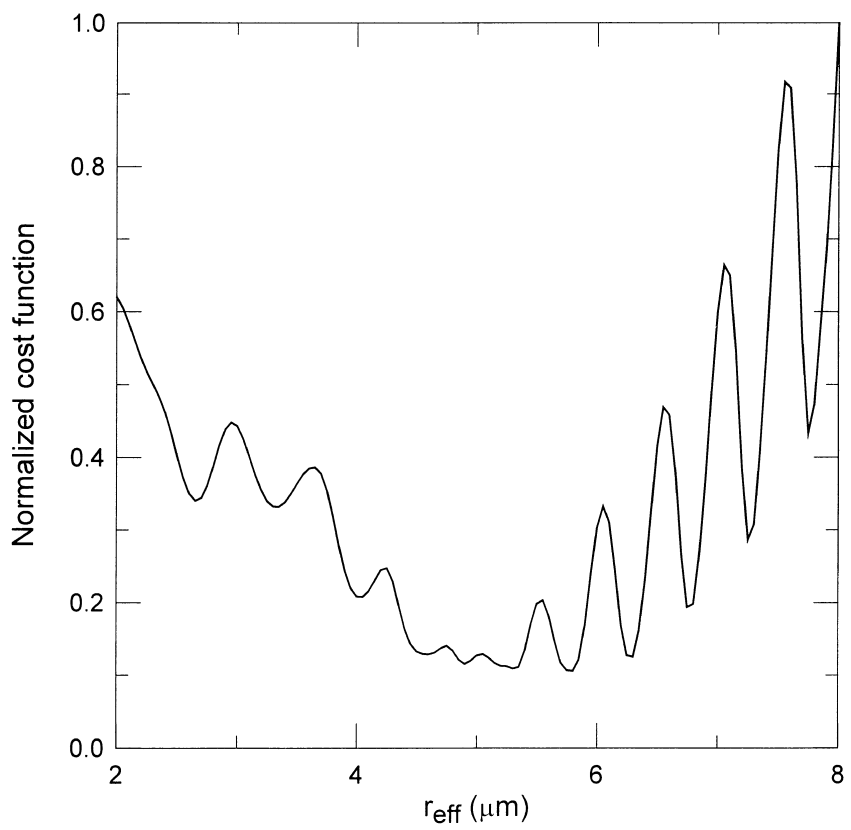

radius. As we can see, the function $A_{34}(r)$ is not monotonic with the radius and, therefore, several effective radii will exist that provide the same curve in a diagram of $\mathrm{BTD}_{34}$ vs. $T_{4}$. This implies that the effective droplet radius cannot be uniquely recovered using only these diagrams.

If we repeat the process for the case of channels 4 and 5, we get the function represented in Fig. 3b. In this case, the function displays nonmonotonic behavior in the $r_{\text {eff }}$ range of $4-7 \mu \mathrm{m}$.

\section{Data Acquisition}

In the present study we used ground-based data and NOAA satellite imagery. The in situ data were acquired during a field campaign carried out by R. Borys and D. Lowenthal (Borys et al., 1998) on the northern corner of Tenerife in the Canary Islands during the summer of 1996. The sampling site, Pico del Inglés $\left(16^{\circ} 16^{\prime} \mathrm{W}\right.$, $28^{\circ} 22^{\prime} \mathrm{N}$ ), is on a ridge at an elevation of $922 \mathrm{~m}$. As already mentioned, the height of the inversion layer is lowest during the summer period, and the sampling site is frequently immersed in the cloud layer. In-cloud microphysical measurements can be made directly from the ground, in an atmosphere that represents the marine atmospheric boundary layer of the eastern tropical Atlantic Ocean. Notably, there are no significant pollution sources upwind of the site.

Cloud microphysical and bulk cloud water chemical sampling was conducted from a $10-\mathrm{m}$ tower at night, to avoid ground-induced heating and cloud dissipation and to minimize contamination from vehicular traffic (Borys et al., 1998). The droplet size distribution was obtained from a PMS Forward Scattering Spectrometer Probe (FSSP$100 \mathrm{HV}$ ) optical sensor. The data were integrated continuously over 60 -s intervals and averaged over 30 -min peri- 

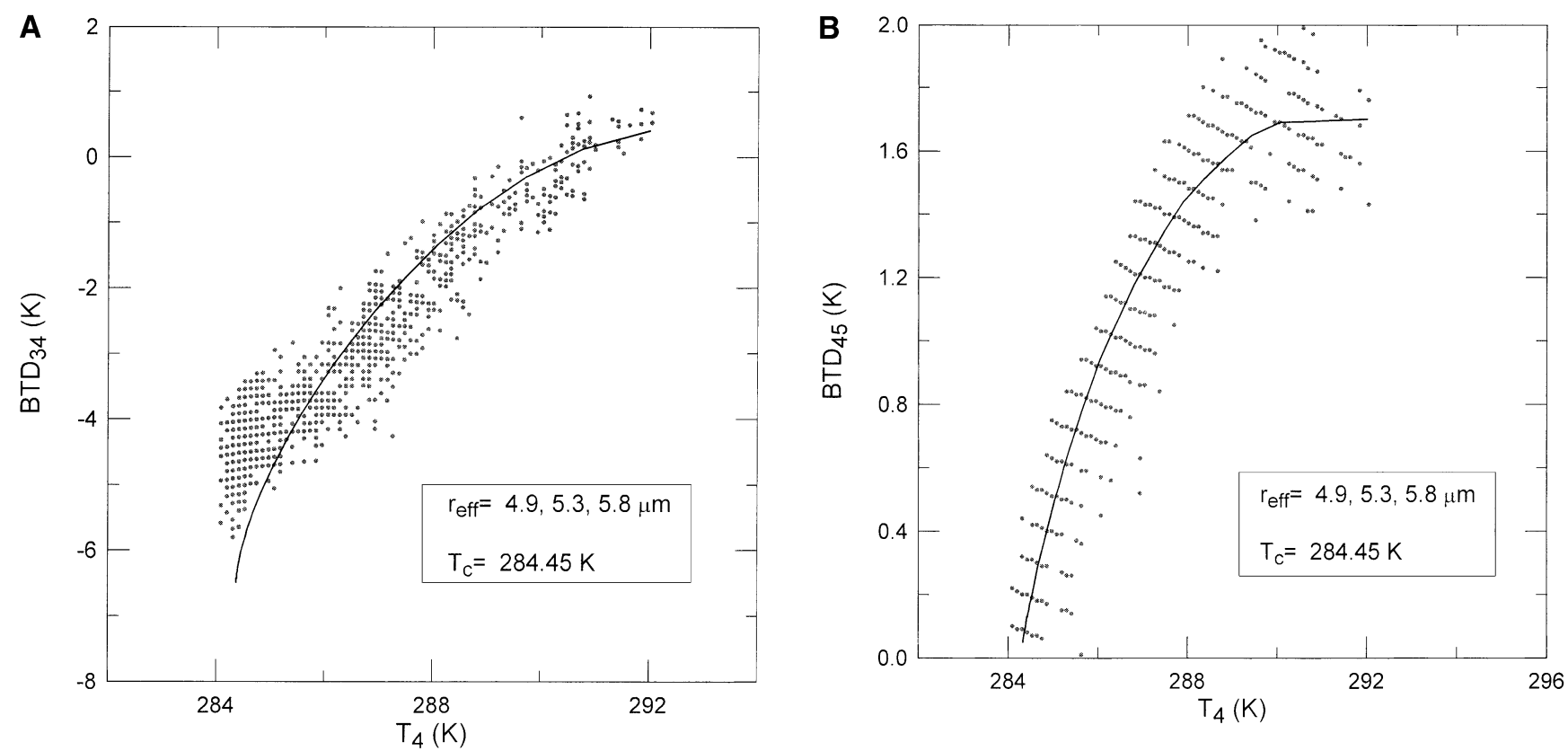

Figure 11. Case B scattergrams with the best fits obtained through the proposed method in both the (a) BTD 34 and (b) BTD ${ }_{45}$ diagrams.

ods. These data were collected from nightfall to midnight. The tower sampling method is estimated to represent the midpoint of the cloud, and is both close to the orographic cloud base, located down the slope at an elevation about 100-200 m below the sampling location, and close to the cloud top, as estimated from balloon soundings and comparisons of in situ cloud temperature and satellite estimates of cloud top temperatures.

Image data included in this study consist of High Resolution Picture Transmission (HRPT) data from NOAA-AVHRR received at the Communication and Remote Sensing Laboratory at the University of La Laguna, Tenerife, Canary Islands. These data are collected and processed using TeraScan equipment and software developed by SeaSpace Corporation.

We used data from the NOAA-14 satellite because it crosses our station at approximately 0300 GMT, closest to the in situ observation time. Therefore, we only used thermal AVHRR channels, with digital values converted to brightness temperatures using temperature-specific channel calibration coefficients extracted from calibration parameters transmitted by the satellite, and the Planck blackbody function (Kidwell, 1995). A slight nonlinearity in channels 4 and 5 is corrected using a quadratic function of radiance (Young, 1995).

Satellite imagery were analyzed for every day for

Table 1. Results Obtained for the Whole Dataset

\begin{tabular}{cccc}
\hline & In situ measurements: & \multicolumn{2}{c}{ Extracted parameters } \\
\cline { 3 - 4 } Date & $\begin{array}{c}\text { Time-averaged } \\
\text { effective radius }(\mu \mathrm{m})\end{array}$ & $\begin{array}{c}\text { Cloud temp. } \\
\mathrm{T}_{c}(\mathrm{~K})\end{array}$ & $\begin{array}{c}\text { Effective radii } \\
r_{\mathrm{eff}}(\mu \mathrm{m})\end{array}$ \\
\hline $06-11-95$ & 5.41 & 282.85 & $5.35,5.80,6.30$ \\
$06-22-95$ & 5.07 & 286.15 & $5.95,6.15,6.40,6.70,6.85$ \\
$06-25-95$ & 4.79 & 280.70 & $4.35,4.80,5.25$ \\
$06-29-95$ & 5.67 & 282.70 & $5.70,5.85,6.30$ \\
$06-30-95$ & 5.07 & 284.0 & $4.85,5.30,5.80$ \\
$07-05-95$ & 4.88 & 286.95 & $5.90,6.15,6.40,6.70,6.85$ \\
$07-05-96$ & 9.14 & 284.40 & $7.85,8.25,8.25,8.55,8.75$ \\
$07-07-96$ & 7.61 & 283.45 & $7.35,7.60,7.75,8.05,8.25$ \\
$07-18-96$ & 5.45 & 285.10 & $6.00,6.15,6.40,6.70,6.85$ \\
$07-19-96$ & 5.91 & 284.45 & $4.90,5.30,5.80$ \\
$07-20-96$ & 5.76 & 284.90 & $5.40,5.65,5.85$ \\
$07-25-96$ & 6.29 & 285.70 & $6.45,6.65,6.90,7.05,7.30$ \\
$07-26-96$ & 7.70 & 285.20 & $6.45,6.65,6.90,7.20,7.35$ \\
\hline
\end{tabular}




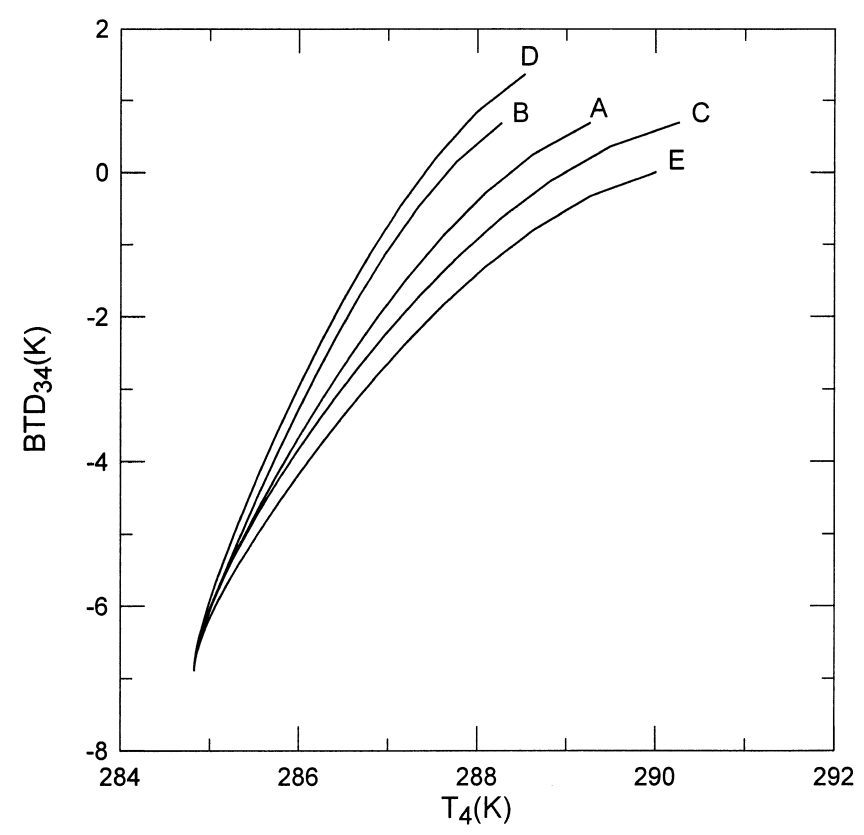

Figure 12. Dependence of $\mathrm{BTD}_{34}$ on underlying surface temperature and atmosphere conditions below the cloud. The curves correspond to droplet effective radius of $5 \mu \mathrm{m}$.

which we have ground-based data. From these, we selected two representative images in order to apply the method developed for retrieval of the effective droplet radius and mean temperature of the stratocumulus layer.

\section{METHOD OF RETRIEVAL AND RESULTS}

With the aim of retrieving the effective droplet radius and cloud temperature from satellite night imagery, we must select areas that contain both cloudless pixels and zones containing very dense clouds. This provides points with diverse optical thickness and so we can superimpose the curves obtained with the theoretical model. If there were no cloudless pixels, we could not estimate the temperature under the cloud $\left(T_{\mathrm{s}}\right)$ for any of the three thermal channels. If there were not optically thick clouds, we could not estimate the temperature of the cloud layer. Without intermediate points, there would exist multiple curves, for several radii, that depart from and arrive at the same points, such that we could not estimate the effective droplet radius.

To find the parameters that provide the curve that fits satellite data within a limited box area on each image, we should invert the model. Due to its complex form, it is not feasible to invert it in analytic form, so we must resort to numerical methods. With this goal, we defined a cost function, dependent on $r_{\text {eff }}$ and $T_{\mathrm{c}}$, that consists of the sum of the distances (to each curve) of data from all the pixels of the selected image area. The process of inversion is therefore based on the search of the minimum of this cost function.

The proposed method will be described using one of the satellite images selected for this study. This allows us to show the different steps using satellite measurements.

\section{CASE STUDY: A}

The first image corresponds to 26 July 1996, showing a quite homogeneous stratocumulus layer to the north of the islands (Fig. 4). As the sampling site was located at

Figure 13. Effect of cloud cover on $\mathrm{BTD}_{34}$ for two effective radii: (a) $5 \mu \mathrm{m}$ and (b) $8 \mu \mathrm{m}$.
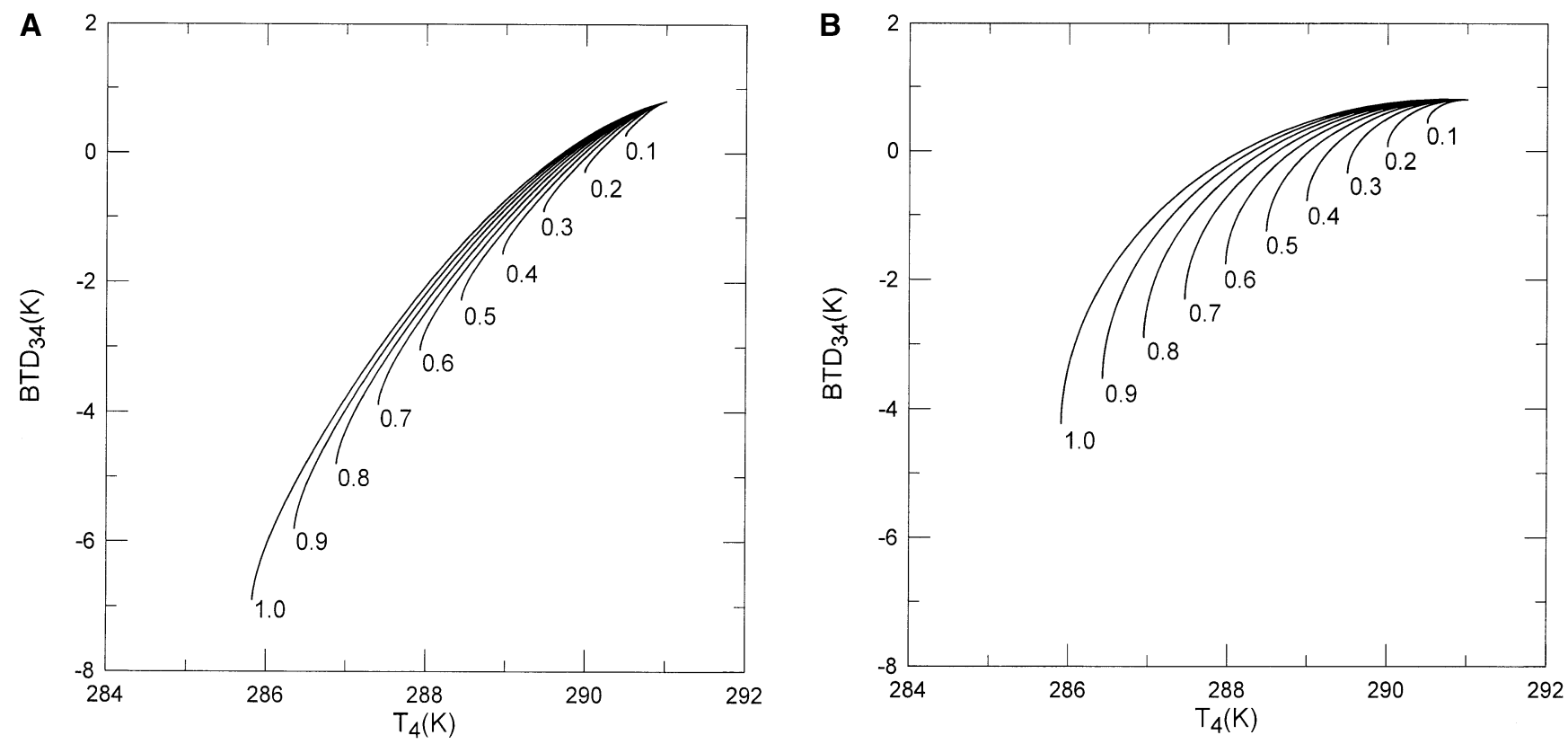

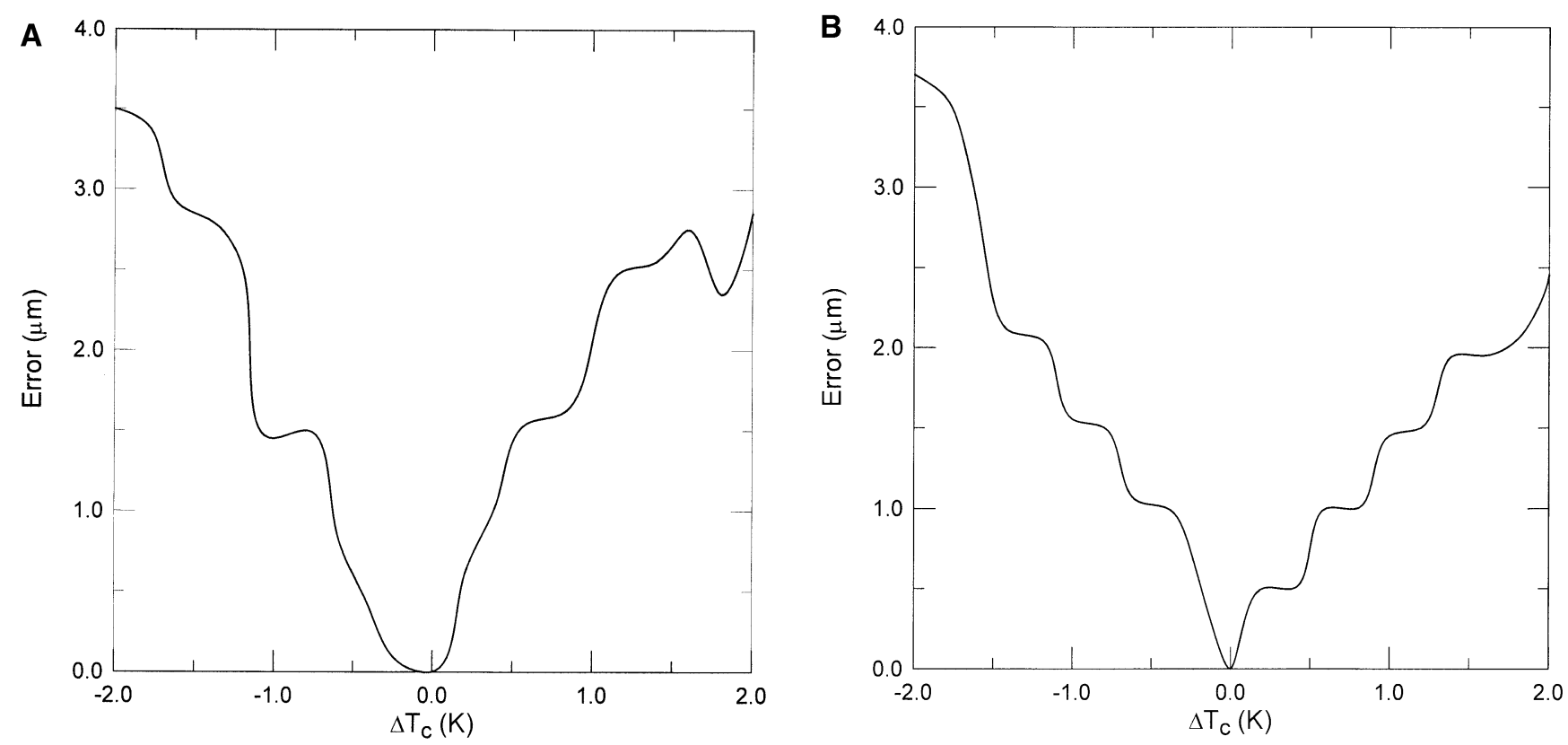

Figure 14. Dependence of the retrieved radii on cloud temperature for the two case studies: (a) 26 July and (b) 19 July.

the north of Tenerife Island, we selected a box that includes a large area to the north of the island.

In Fig. 5a-d, we represent the same curves as shown in Fig. $1 \mathrm{a}-\mathrm{d}$, but with satellite data from the selected box added. We can see that, in general, the model follows the data in both diagrams, but to find the cloud parameters that provide the curves that best fit these data in both diagrams we must search the cost function minima. It is then necessary to know the shape of these cost functions for $\mathrm{BTD}_{34}$ and $\mathrm{BTD}_{45}$ (Fig. 6). In Fig. 6a, we see that in the $\mathrm{BTD}_{34}$ case we cannot use the typical methods used to obtain the minima of a multivariate function because, starting from different initial values for $r_{\text {eff }}$ and $T_{\mathrm{c}}$ into our range of interest, different solutions could be reached that produced a local minimum of cost function.

In the $\mathrm{BTD}_{45}$ case (Fig. 6b), the behavior of the corresponding cost function is less complex. Starting from any point we obtain a convergence in $T_{\mathrm{c}}$, but this diagram is not very sensitive to variations in the radius. Therefore, we will use the Downhill Simplex Method (Press et al., 1992) to obtain only $T_{\mathrm{c}}$ from the $\mathrm{BTD}_{45}$ diagram.

Once this temperature is determined, we compute the theoretical model results for AVHRR Channels 3 and 4 for a wide range of $r_{\text {eff. }}$ We can then find the set of radii that minimize the cost function in the $\mathrm{BTD}_{34}$ diagram. This minimization is made in one dimension, varying only $r_{\text {eff. }}$ The difficulty lies in the choice of these minima; that is, from all local minima of the cost function we must select those that are smaller than the rest, but the problem is to decide the threshold that allows us to distinguish the correct ones. However, we can make use of the phase changes that occur in the cost function.
In Fig. 7 , we represent the $A_{34}$ function and the normalized cost function for this case. As described above, the $A_{34}$ function takes into account the proximity of the curves for each $r_{\text {eff }}$ to the horizontal axis while the cost function reveals the distance from each of these curves to that providing the best fit. For this reason, when the cost function crosses the best fit, a phase change takes place with respect to the $A_{34}$ function. So, in Fig. 7, for radii below $6.4 \mu \mathrm{m}$, both functions reach their maxima and minima for the same $r_{\text {eff }}$ values. Then some phase changes can be appreciated and, for large values, both functions are in opposite phase. Therefore, from this behavior we can extract the effective radii. The method is faster and simpler than using only the $\mathrm{BTD}_{34}$ diagram to obtain both $T_{\mathrm{c}}$ and $r_{\text {eff }}$.

Applying this method we obtain, for the present case A, a cloud layer temperature $T_{\mathrm{c}}=285.2 \mathrm{~K}$ and effective radii $r_{\text {eff }}=6.45,6.65,6.9,7.20$, and $7.35 \mu \mathrm{m}$. These are the values where phase changes were detected. The measurements taken by the PMS Forward Scattering Spectrometer for this day were made between 2030 and 2230 GMT, supplying a time-averaged effective radius of $7.7 \mu \mathrm{m}$ for this stratocumulus layer. In Fig. 8 we present the $\mathrm{BTD}_{34}$ vs. $T_{4}$ and $\mathrm{BTD}_{45}$ vs. $T_{4}$ diagrams for this box and, superimposed, the theoretical curves with $T_{\mathrm{c}}$ and $r_{\text {eff }}$ that provide the best fit.

\section{CASE STUDY: B}

The second image included to show the behavior of the theoretical model corresponds to 19 July 1996 (Fig. 9). We can see a large area to the north of the archipelago covered by dense and homogeneous stratocumulus. This 

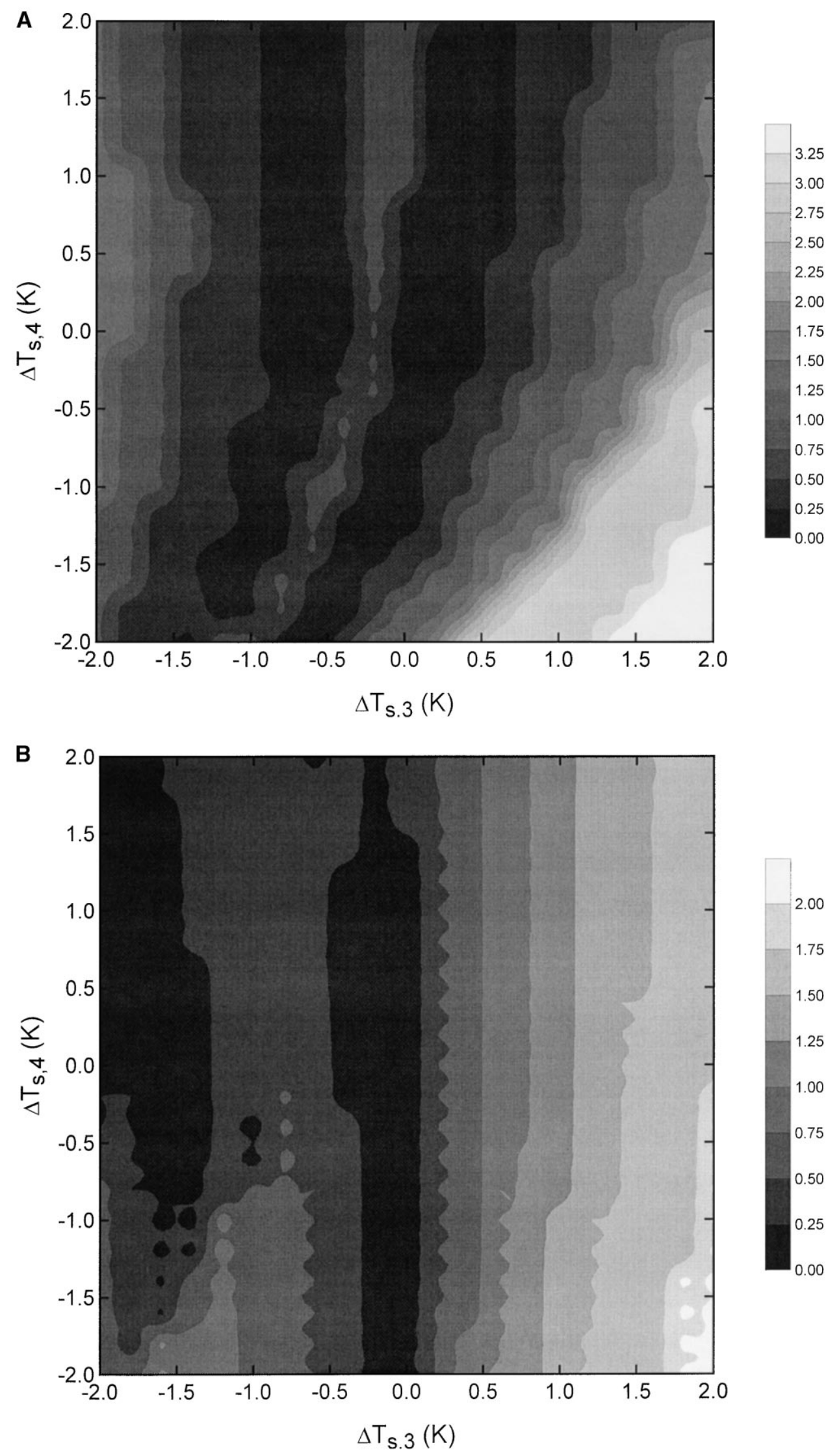

Figure 15. Dependence of the retrieved radii on clear-sky temperatures in channels 3 and 4 for the two case studies: (a) 26 July and (b) 19 July. 
wide layer presents some inconvenience because, as already noted, we cannot determine $T_{\mathrm{s}}$ if we do not have any clear pixels and it is difficult to extract $r_{\text {eff }}$. For this reason, we selected a box that contains pixels with varying optical depth. This box is shown in Fig. 9. In the same way as we proceeded in case A, we obtain a cloud temperature of $284.45 \mathrm{~K}$ and $r_{\text {eff }}=4.9,5.3$, and $5.8 \mu \mathrm{m}$ (Fig. 10). In Fig. 11, we present the $\mathrm{BTD}_{34}$ vs. $T_{4}$ and $\mathrm{BTD}_{45}$ vs. $T_{4}$ diagrams with the best fits. In this case, the measurements at the sample site were made between 19:30 and 21:15 GMT and the effective radius measured during this period averaged was $5.9 \mu \mathrm{m}$.

\section{RESULTS}

The method just described and exemplified has been applied to those days when in situ measurements and night satellite data were available. Table 1 shows the results obtained for both cloud temperatures and discrete effective radii, and gives the time-averaged effective radii measured in the summer 1995 and 1996 campaigns. From this table we can see how the measured radii are very similar during the 1995 campaign, but those for 1996 present a greater variation. In any case, the in situ measured cloud droplet radii fall within the range of 4.5$11.0 \mu \mathrm{m}$.

The extracted effective droplet radii are, in general, in accordance with those obtained at Pico del Inglés. On some days, however, such as on 22 June 1995, the large difference between the retrieved and measured values are due to the difficulty in obtaining a box near the sampling site that satisfies the above-mentioned requirements.

\section{Sensitivity Study}

The set of radii obtained through the proposed method are controlled by the parameters fixed at the beginning of the procedure (i.e., cloud and clear-sky temperatures). Uncertainties in any of these parameters will influence the accuracy of the retrieval. Furthermore, we must bear in mind the effect of broken clouds. Thus, we present a sensitivity study of the method and apply it to the two case studies.

The cloud temperature is retrieved from channels 4 and 5, as explained above. An error in this temperature extraction causes a displacement of the curves, as discussed above under Model Behavior (Fig. 1b). In general, when the cloud temperature is underestimated the retrieved radii will be also underestimated and vice versa, as can be appreciated from Figs. 1a and 1b. However, this behavior is only a general trend because of the above-mentioned model oscillations when the radius is varied.

In addition, the clear-sky temperatures, obtained from cloudless pixels, determine the radiance reaching the cloud bottom. They therefore play an important role in the retrieval method, because they fix the starting point of curves in the $\mathrm{BTD}_{34}$ diagram. Figure 12 presents the model behavior for a particular radius, $5 \mu \mathrm{m}$, and several conditions for the underlying surface and the atmosphere below the cloud. Curve A is the reference curve. Curves B and C correspond to changes in the surface temperature that, as we can see, lead to displacements that are more important in the $T_{4}$ axis. However, changes in atmospheric conditions, such as variations in water vapor content, produce significant changes in both axes (curves D and E). Thus, the combination of both effects could cause displacements in any direction. Again, as a general trend, when the perturbed curve is on the left of the reference curve the retrieved radii are smaller, because when the radius decreases curves are displaced to the right.

Next, we look at the effect of considering broken clouds in the theoretical model. Figure 13 shows the model behavior when cloud cover is varied from 0 to 1 for two effective radii: $5 \mu \mathrm{m}$ (Fig. 13a) and $8 \mu \mathrm{m}$ (Fig. $13 \mathrm{~b})$. We can see that the main effect on the $\mathrm{BTD}_{34}$ diagram is the broadening of the scattergram. Curves with cloud cover less than 1 are below the curve representing totally covered pixels. If we assumed that the histogram broadening is due only to this effect, we would fit the theoretical curves to the upper left edge of the scattergram. However, the shape of the histogram depends also on the other factors, cloud and clear-sky temperatures. We therefore defined our cost function in terms of least squares.

Finally, we examine how small errors in the estimation of cloud and clear-sky temperatures affect the radii retrievals for the two case studies. Figure 14 presents the differences between the central radius of the set of retrieved radii for the selected cloud temperature, $T_{\mathrm{c}, \text { reff, }}$, and the central radius for other cloud temperatures, varying from $T_{\mathrm{c}, \text { reff }}-2 \mathrm{~K}$ to $T_{\mathrm{c} \text {,reff }}+2 \mathrm{~K}$. Figure $14 \mathrm{a}$ corresponds to the case A study and, as we can appreciate, errors greater than $3 \mu \mathrm{m}$ are obtained when uncertainties in the cloud temperature are about $2 \mathrm{~K}$. However, these displacements can be easily detected on the $\mathrm{BTD}_{34}$ diagram. Nevertheless, when the cloud temperature variations remain below $0.5 \mathrm{~K}$ the errors are under $1 \mu \mathrm{m}$. Similar results are seen for the 19 July case (Fig. 14b).

In the same way, we analyzed the effects of accuracy in determination of clear-sky temperatures on the effective radius retrieval. Figure 15 shows the errors when the temperatures in channels 3 and 4 are varied. The dependence on channel 3 variations is stronger, because when we displace vertically the starting point of the curves in the $\mathrm{BTD}_{34}$ diagram, there do not exist radii that provide good fits to the satellite data. Also, the uncertainties in channel 4 temperature cause significant errors in the radii. Again, these deviations in the clear-sky temperatures are easily appreciated when the theoretical curves are su- 
perimposed on satellite data, and small variations (below $0.5 \mathrm{~K})$ lead to errors less than $0.5 \mu \mathrm{m}$. Therefore, as can be deduced, the dependence on cloud temperature is stronger than on clear-sky temperatures; however, both effects must be taken into account.

\section{Concluding Discussion}

A methodology for the retrieval of the characteristic parameters of low clouds has been developed using nighttime data from the NOAA-AVHRR thermal channels and a radiative transfer model based on the DISORT numerical algorithm. In this way, using channel 4 and 5 data, the mean temperature of the cloud layer is obtained and, from it, the effective radius of droplets is obtained using channels 3 and 4 .

We examined the difficulty encountered when the theoretical model is inverted, because several effective radius and cloud temperature values exist that provide the same thermal channel temperatures. Furthermore, this behavior makes it difficult to use a procedure based on the discretization of the effective radius and then interpolate the results obtained from satellite data, because two similar radii can provide quite different radiative characteristics.

We applied the proposed method to images corresponding to days when in situ measurements were made. In one of the selected images, case $\mathrm{A}$, we obtained five values for the effective radius, but we cannot choose one as the correct value because they all yield similar curves in the $\mathrm{BTD}_{34}$ diagram. This set of radii cannot be considered as a continuous interval, since a value belonging to this interval could provide a $\mathrm{BTD}_{34}$ curve quite far from the satellite data. For this day, the smallest difference between the radius measured by the PMS spectrometer and one of the radii retrieved from the AVHRR data is $0.35 \mu \mathrm{m}$; the largest is $1.25 \mu \mathrm{m}$. In the same way, for the case B study the closest value differs by $0.1 \mu \mathrm{m}$, and by $1 \mu \mathrm{m}$ for the worst case. In both cases the computed radii are smaller than the values obtained in situ, but this is not the general behavior found in the whole data set (as can be seen from Table 1).

Nevertheless, to compare in situ data with the satellite measurements of the cloud top, we must bear in mind that the PMS spectrometer was located approximately at the midpoint of the cloud and, as is known, particle size within the cloud increases generally from the base to the top due to collision and coalescence. However, the clouds sampled in the field experiment are considered to be of very limited vertical extent (less than $400 \mathrm{~m}$ ), and therefore the vertical variability in droplet size is similarly limited.

Moreover, we must keep in mind that, in spite of the uncertainties of the method studied, there are two other factors that could provide differences between retrieval values and in situ measurements. The require- ment of selecting a box that contains both clear regions and regions with optically thick clouds implies that, sometimes, we cannot choose this box near the sampling site. Also, time differences exist between the satellite overpass and the in situ observations.

In all the cases analyzed we can find a retrieved value that differs less than the $0.4 \mu \mathrm{m}$ obtained by the PMS spectrometer, although the problem is to distinguish this radius from others supplied by the method. Nevertheless, this method is capable of estimating a discrete set of sizes of cloud particles, and warrants further study.

The authors wish to express their gratitude to Consejería de Educación of the Canary Islands Government (Project 4/95) for financial support. The work of the coauthors from the Desert Research Institute was supported by the U.S. National Science Foundation, Grant ATM-9408660. The authors also wish to acknowledge the reviewers, who made several helpful suggestions after reviewing an earlier version of this paper.

\section{REFERENCES}

Baum, B. A., Arduini, R. F., Wielicki, B. A., Minnis, P., and Tsay, S. (1994), Multilevel cloud retrieval using multispectral HIRS and AVHRR data: nighttime oceanic analysis. J. Geophys. Res. 99:5499-5514.

Bohren, C. F., and Huffman, D. R. (1983), Absorption and Scattering of Light by Small Particles, John Wiley, New York.

Borys, R. D., Lowenthal, D. H., Wetzel, M. A., Herrera, F., Gonzalez, A., and Harris, J. (1998), Chemical and microphysical properties of marine stratus clouds in the North Atlantic. J. Geophys. Res. 103:22073-22085.

Dave, J. V. (1970), Coefficients of the Legendre and Fourier series for the scattering functions of spherical particles. Appl. Opt. 9:1888-1896.

Hansen, J. E., and Travis, L. D. (1974), Light scattering in planetary atmospheres. Space Sci. Rev. 16:527-610.

Herrera, F., Rosa, F., González, A., and Pérez, J. C. (1999), Method based in a radiative transfer model to extract the solar component from NOAA-AVHRR channel 3. Int. J. Remote Sens. 20:699-710.

Hutchison, K. D., Hardy, K. R., and Gao, B. (1995), Improved detection of optically thin cirrus clouds in nighttime multispectral meteorological satellite imagery using total integrated water vapor information. J. Appl. Meteorol. 34: 1161-1168.

Hutchison, K. D., Mack, J., McDonald, R., and Logan, G. (1991), The positive identification of optically-thin cirrus in nighttime, multispectral meteorological satellite imagery by automated cloud detection and typing algorithms. In Proc. on the Cloud Impacts on DoD Operations and Systems 1991 Conf. Los Angeles, CA, Air Force Phillips Laboratory, Kirtland A.F.B., NM, pp. 305-309.

Kidwell, K. B. (1995), NOAA Polar Orbiter Data Users Guide (TIROS-N, NOAA-6, NOAA-7, NOAA-8, NOAA-9, NOAA10, NOAA-11, NOAA-12, NOAA-13, and NOAA-14), NESDIS, NOAA, Washington, DC. 
Marzol, M. V., Dorta, P., Valladares, P., Morín, P., Sánchez Megía, J. L., and Abreu, M. (1994), La captation de l'eau à Tenerife (Îles Canaries). L'utilization des Broulliards. Publications de l'Association Internationale de Climatologie 7:83-91.

Marzol, M. V., Rodríguez, J., Arozarena, C., and Luis, M. (1988), Rapport entre la dynamique de la mer de nuages et la vegetation au Nord de Tenerife (Iles Canaries). Publications de l'Association Internationale de Climatologie 1: 273-283.

Nussenzveig, H., and Wiscombe, W. (1980), Efficiency factors in Mie scattering. Phys. Rev. Lett. 45:1490-1494.

Ou, S. C., Liou, K. N., Gooch, W. M., and Takano, Y. (1993), Remote sensing of cirrus cloud parameters using advanced very-high-resolution radiometer 3.7 - and $10.9-\mu \mathrm{m}$ channels. Appl. Opt. 32:2171-2180.

Press, W. H., Teukolsky, S. A., Vetterling, W. T., and Flannery, B. P. (1992), Numerical Recipes in C: The Art of Scientific Computing (2nd ed.), Cambridge University Press, Cambridge, pp. 408-412.

Rao, N. X., Ou, S. C., and Liou, K. N. (1995), Removal of the solar component in AVHRR $3.7 \mu \mathrm{m}$ radiances for the retrieval of cirrus cloud parameters. J. Appl. Meteorol. 34: 482-499.
Seglestein, D. (1981), The complex refractive index of water. M.S. thesis, University of Missouri-Kansas City.

Stamnes, K., Tsay, S., Wiscombe, W., and Jayaweera, K. (1988), Numerically stable algorithm for discrete-ordinatemethod radiative transfer in multiple scattering and emitting layered media. Appl. Opt. 27:2502-2509.

Tsay, S., Stamnes, K., and Jayaweera, K. (1990), Radiative transfer in stratified atmospheres: development and verification of a unified model. J. Quant. Spectrosc. Radiat. Transfer 43:133-148.

Twomey, S. (1977), The influence of pollution on the shortwave albedo of clouds. J. Atmos. Sci. 34:1149-1152.

Twomey, S., Piepgrass, M., and Wolfe, T. L. (1984), An assessment of the impact of pollution on global cloud albedo. Tellus 36B:356-366.

Wen, S., and Rose, W. I. (1994), Retrieval of sizes and total masses of particles in volcanic clouds using AVHRR bands 4 and 5. J. Geophys. Res. 99:5421-5431.

Wetzel, M. A., Borys, R. D., and Xu, L. E. (1996), Satellite microphysical retrievals for land-based fog with validation by balloon profiling. J. Appl. Meteorol. 35:810-829.

Wiscombe, W. (1980), Improved Mie scattering algorithms, Appl. Opt. 19:1505-1509.

Young, T. L. (1995), TeraScan Reference Manual, Seaspace, San Diego. 